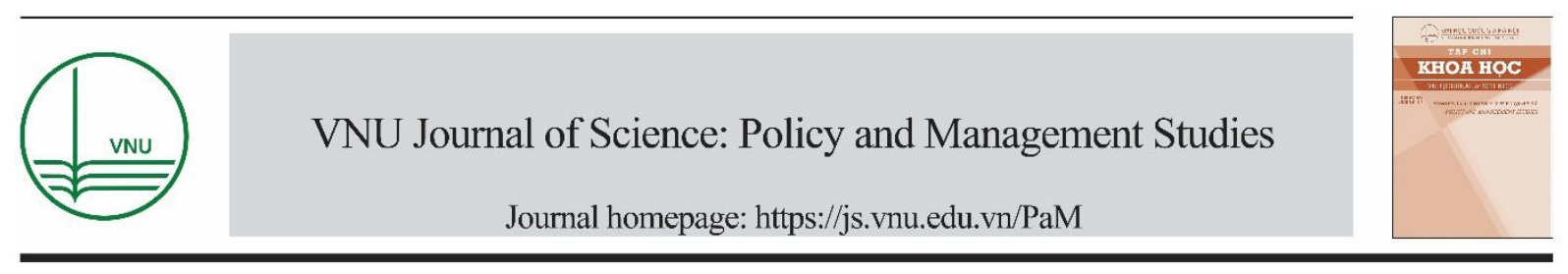

Original Article

\title{
Production Waste at the Tapioca Processing Factories in Central Highlands
}

\author{
Phan Thi Thanh Truc*, Nguyen Ngoc Thao Vy \\ The University of Danang - Campus in Kon Tum, 704 Phan Dinh Phung, \\ Quang Trung, Kon Tum City, Kon Tum, Vietnam \\ Received 18 January 2019 \\ Revised 13 March 2019; Accepted 13 March 2019
}

\begin{abstract}
This paper assesses the situation of production waste at the tapioca starch processing factories in Central Highlands. The results of expert interview and 250 employees' and factories managers' structured questionnaires show that the production waste was at a high level due to production imbalance, frequent equipment malfunction and unstandardized production procedures. The paper proposes the signing of contracts between the factories and the local farmer to ensure a production balance, technological upgrades, standardization of production procedures, and the development of relevant policies to encourage the workers to make efforts to enhance the production procedures, which helps factories reduce waste in production.
\end{abstract}

Keywords: Waste, tapioca starch, Central Highlands.

\footnotetext{
${ }^{*}$ Corresponding author.

E-mail address: thanhtruckontum@gmail.com
}

https://doi.org/10.25073/2588-1116/vnupam.4166 


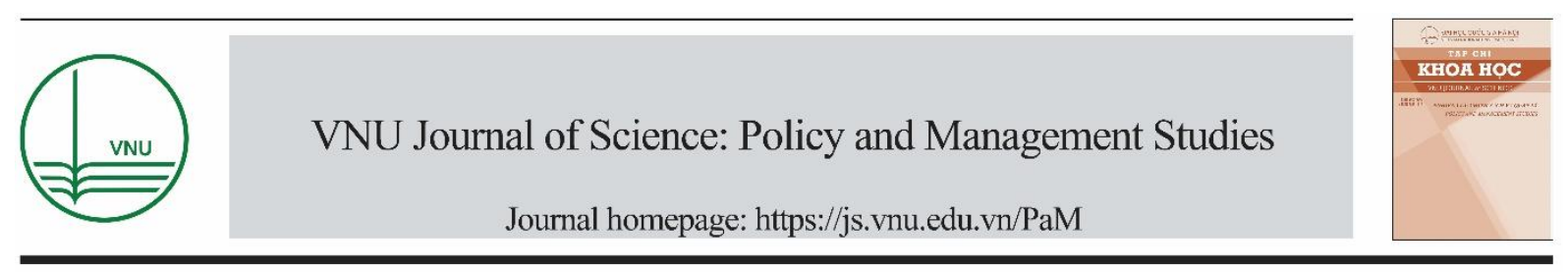

\title{
Lãng phí sản xuất tại các doanh nghiệp chế biến tinh bột sắn khu vực Tây Nguyên
}

\author{
Phan Thị Thanh Trúc*, Nguyễn Ngọc Thảo Vy \\ Phân hiệu Đại học Đà Nã̃ng tại Kon Tum, 704 Phan Đình Phùng, \\ Quang Trung, TP. Kon Tum, Kon Tum, Việt Nam \\ Nhận ngày 18 tháng 01 năm 2019 \\ Chỉnh sửa ngày 13 tháng 3 năm 2019; Chấp nhận đăng ngày 13 tháng 3 năm 2019
}

\begin{abstract}
Tóm tắt: Nghiên cứu này tập trung đánh giá thực trạng lãng phí sản xuất tại các nhà máy chế biến tinh bột sắn tại Tây Nguyên. Thông qua phương pháp phỏng vấn bằng chuyên gia, phỏng vấn bằng bảng câu hỏi 250 nhân viên và cán bộ quản lý tại các nhà máy, kết quả cho thấy lãng phí trong sản xuất như không có sự cân bằng trong sản xuất, thiết bị hỏng hóc, không ổn định, quy trình chưa được chuẩn hóa, các thao tác mỗi công nhân mỗi khác nhau, các khuyết tật lặp đi lặp lại không có các biện pháp đề xuất cải tiển... ở mức lãng phí cao. Bài báo đề xuất cần có sự ký kết giữa nhà máy với hộ nông dân nhằm đảm bảo sự cân bằng trong sản xuất, nâng cấp công nghệ, chuẩn hóa quy trình, xây dựng các chính sách khuyết khích người lao động đưa ra các sáng kiến cải thiện quy trình. Điều này sẽ giúp các nhà máy giảm thiểu được các lãng phí trong sản xuất.
\end{abstract}

Tì khóa: Lãng phí, tinh bột sắn, Tây Nguyên...

\section{1. Đặt vấn đề}

Sắn và tinh bột sắn (TBS) là một trong mười mặt hàng xuất khẩu chủ lực của Việt Nam. Tính đến tháng 6 năm 2018, tổng sản lượng xuất khẩu sắn và các sản phẩm từ sắn ước đạt 1,5 triệu tấn tấn với 560 triệu USD, giảm về lượng là $24,6 \%$ nhưng tăng $12,3 \%$ về giá trị so với cùng kỳ năm 2017 [1]. Đồng thời, đầu năm 2018, Thái Lan trở

\footnotetext{
*Tác giả liên hệ.

Địa chi email: thanhtruckontum@gmail.com
}

https://doi.org/10.25073/2588-1116/vnupam.4166 thành nước xuất khẩu đứng đầu thế giới về tinh bột sắn, chất lượng cao hơn và giá bán thấp hơn so với Việt Nam. Điều này đặt ra thách thức lớn trong cạnh tranh cho các doanh nghiệp Việt Nam sản xuất tinh bột sắn.

Hiện sắn được trồng và sản xuất nhiều tại Tây Ninh, Kon Tum và Gia Lai. Diện tích trồng sắn tại khu vực Tây Nguyên lớn nhất cả nước. Số lượng doanh nghiệp chế biến tinh bột sắn tại khu vực này cũng gia tăng nhanh chóng. Các nhà máy sản xuất được thành lập từ 10-15 năm, công nghệ được sử dụng chủ yếu từ Trung Quốc, Thái Lan; dây chuyền sản xuất thu hồi khoảng $80 \%$, chất 
lượng sản phẩm thấp hơn các địa phương khác và Thái Lan về độ trắng, độ mịn, tạp chất... chi phí sản xuất chiếm tỷ lệ cao trong tổng chi phí. Vấn đề đặt ra cho các doanh nghiệp chế biến tinh bột sắn tại khu vực Tây Nguyên là làm sao giảm thiểu các chi phí trong sản xuất, hạ giá thành và cải thiện về chất lượng sản phẩm nhằm hướng tới nâng cao năng lực cạnh tranh trên thị trường.

Để giải quyết vấn đề trên, hiện nay có rất nhiều doanh nghiệp áp dụng mô hình quản trị tinh gọn nhằm giúp giảm $50 \%$ thời gian sản xuất chính, 80\% chi phí sản xuất kinh doanh, 30\% mặt bằng sản xuất đồng thời giúp tăng $30 \%$ năng suất lao động [2]. Do vậy, nghiên cứu này nhằm đánh giá hiện trạng các lãng phí trong sản xuất tinh bột sắn của các doanh nghiệp trên địa bàn khu vực Tây Nguyên, từ đó làm căn cứ để cải thiện hoạt động này trong thời gian tới thông qua các công cụ quản trị tinh gọn.

\section{Cơ sở lý luận và phương pháp nghiên cứu}

\subsection{Co sở lýluận}

Sản xuất tinh gọn được hiểu "là phương pháp quản trị định hướng vào việc giảm thiểu lãng phí để nâng cao năng suất, chất lượng, hiệu quả cho toàn bộ quá trình sản xuất. Ý tường sản xuất tinh gọn nhằm nâng cao tối đa giá trị gia tăng khách hàng dựa trên việc triệt để loại bỏ lãng phí trong tất cả các công đoạn tạo ra sản phẩm và dịch vụ, kể từ lúc được sản xuất tới tiêu dùng" [3].

Quản trị tinh gọn là hệ thống các phương pháp được áp dụng trong doanh nghiệp nhằm loại bỏ lãng phí, giảm thiểu thời gian sản xuất, nâng cao năng suất và lợi nhuận. Mô hình quản trị tinh gọn giúp doanh nghiệp phát hiện, nhận dạng lãng phí, từ đó sử dụng các công cụ, phương pháp khoa học để giảm thiểu tối đa các hoạt động không tạo ra giá trị tăng thêm trong quá trình sản xuất kinh doanh [4].

Trong sản xuất kinh doanh, doanh nghiệp đều hướng tới sự tăng trưởng lợi nhuận với Lợi nhuận= Tổng Doanh thu- Tổng chi phí. Trong đó, Tồng chi phí = Chi phí cần thiết + Lãng phí.
Lãng phí được hiểu là tất cả các hoạt động tiêu tốn thời gian, nguồn lực hoặc không gian mà không tạo nên giá trị cho sản phẩm và dịch vụ cho khách hàng [3].

Jeffrey K.Liker sau khi quan sát và tìm hiểu hệ thống sản xuất của Toyota đã đề xuất các loại lãng phí bao gồm: Sản xuất thừa, Thời gian chờ, Vận chuyển không cần thiết, Gia công quá mức cần thiết hoặc không chính xác, Tồn kho quá mức, Chuyển động thừa, Khuyết tật, Không khai thác sức sáng tạo của người lao động [4].

Các lãng phí trong doanh nghiệp sản xuất bao gồm [5]:

+ Chờ đợi: Thời gian công nhân, máy móc nhàn rỗi do tắc nghẽn luồng sản phẩm.

+ Di chuyển: Sự dịch chuyển nguyên vật liệu không tạo ra giá trị gia tăng cho sản phẩm

+ Gia công thừa: Sử dụng quá nhiều nguồn lực không cần thiết vào sản xuất.

+ Tồn kho: Dự trữ quá mức cần thiết về nguyên vật liệu, bán thành phẩm, thành phẩm

+ Thao tác thừa: Thao tác không cần thiết xảy ra trong quá trình sản xuất do thiếu các quy trình, quy chuẩn hoặc công tác đào tạo không hiệu quả

+ Lỗi: Sản phẩm/ dịch vụ lỗi, cần phải sửa chữa

+ Sản xuất thừa: Sản xuất vượt quá định mức mà khách hàng yêu cầu

Để tiết kiệm chi phí, các doanh nghiệp nên áp dụng quản trị tinh gọn bằng những công cụ đòi hỏi sự đầu tư tài chính ít như $5 \mathrm{~S}$, Kaizen, Quản lý trực quan, JIT, TQM (Quản trị chất lượng toàn diện)... Bên cạnh đó, bốn chiến lược thực hiện tinh gọn và loại trừ lãng phí bao gồm: (1) đồng bộ hóa cung cấp cho khách hàng bên ngoài; (2) Đồng bộ hóa sản xuất bên trong; (3) tạo ra dòng chảy; (4) Hình thành hệ thống kéo theo nhu cầu [3].

\subsection{Phuoong pháp nghiên cứu}

Bài báo sử dụng phương pháp tổng hợp, phân tích các dữ liệu từ các bài báo, giáo trình, niêm giám thống kê, các đề án của các địa phương khu vực Tây Nguyên nhằm có góc nhìn tổng quan về tình hình sản xuất tinh bột sắn tại khu vực Tây Nguyên. 
Bên cạnh đó, để đánh giá được thực trạng về các loại lãng phí trong sản xuất, bảng câu hỏi được xây dựng dựa trên các loại lãng phí được trích trong [3].

Quy trình thực hiện bao gồm 2 giai đoạn:

Giai đoạn 1: sử dụng phương pháp phỏng vấn chuyên gia. Nhóm gửi bảng câu hỏi các loại lãng phí trong sản xuất ngành chế biến tinh bột sắn lần lượt tới 5 giám đốc của các nhà máy tại Kon Tum (tại Sa Bình, Sa Nhơn, ĐăkGlei, Đăk Hà, Đăk Tô). Sau khi thu bảng hỏi về lần 1 , nhóm loại bỏ loại lãng phí theo đánh giá của các chuyên gia. Bảng hỏi được gửi qua email hiệu chỉnh lần 2 . Sau khi thu bảng hỏi về, tất cả các giám đốc đều đồng ý với các loại lãng phí dựa trên quy trình sản xuất mà các nhà máy đang tiến hành, bảng hỏi được sử dụng để đánh giá ở giai đoạn 2.

Bảng câu hỏi thực hiện đánh giá thực trạng lãng phí giai đoạn 2 bao gồm các nội dung:

Phần 1: Thông tin chung, mô tả thông tin cơ bản của mẫu

Phần 2: Nội dung trao đổi đánh giá các loại lãng phí.

Giai đoạn 2: Đánh giá các loại lãng phí thông qua phỏng vấn bảng câu hỏi.
Bảng câu hỏi được gửi đến người được khảo sát dưới hai hình thức là phỏng vấn trực tiếp với cách thức thứ nhất, tác giả trực tiếp phỏng vấn và giải thích thắc mắc cho người được khảo sát, người được khảo sát điền vào phiếu, sau 30 phút tác giả thu lại, cách này thực hiện khó khăn nhưng khả năng thu lại mẫu gần như $100 \%$. Đối với cách thức thứ hai, mang tính thuận tiện cao hơn vì người được khảo sát đỡ tốn kém hơn về chi phí đi lại, nhưng khó có thể trao đổi trong thời gian dài, chỉ có thể hỏi và trao đổi những câu hỏi ngắn gọn, nên cách thứ hai chỉ áp dụng với số lượng ít, chỉ khoảng $10 \%$ bảng hỏi khảo sát.

Bài viết sử dụng phương pháp thống kê mô tả, tính giá trị trung bình được sử dụng để đánh giá mức độ quan trọng của các loại lãng phí. Tiêu chí xếp hạng như sau:

Bảng 1. Quy ước thang đánh giá mức độ lãng phí

\begin{tabular}{ll}
\hline Mức độ & $\begin{array}{l}\text { Điểm trung } \\
\text { bình/câu (tiêu chí) }\end{array}$ \\
\hline Lãng phí nhiều & $>3.50$ \\
Lãng phí khá nhiều & $3.00-3.500$ \\
Lãng phí trung bình & $2.50-2.99$ \\
Lãng phí thấp & $<2.50$ \\
\hline
\end{tabular}

- Thông tin cỡ mẫu khảo sát

Bảng 2. Thống kê đối tượng khảo sát theo khu vực khảo sát

\begin{tabular}{lllcc}
\hline STT & Tiêu chí & & Tần suất & Tỷ lệ \\
\hline 1 & Cách thức thu & Google doc & 180 & $72 \%$ \\
& thập dữ liệu & Bằng giấy & 70 & $28 \%$ \\
\multirow{3}{*}{2} & Số doanh nghiệp & Kon Tum (6) & 130 & $52 \%$ \\
& tại Địa phương (13) & Gia Lai (5) & 80 & $32 \%$ \\
& & Đăk Lăk (2) & 40 & $16 \%$ \\
3 & \multirow{3}{*}{ Kinh nghiệm làm việc } & $<1$ năm & 57 & $22,8 \%$ \\
& & $1-3$ năm & 130 & $52 \%$ \\
& & Trên 3 năm & 63 & $25,2 \%$ \\
4 & Vị trí công tác & Nhân viên & 220 & $88 \%$ \\
& & Quản lý & 30 & $12 \%$ \\
Tổng & & & 250 & $100 \%$ \\
\hline
\end{tabular}

Nguồn: Tổng hơp của nhóm nghiên cúu 


\section{Thực trạng các loại lãng phí sản xuất các doanh nghiệp chế biến tinh bột sắn tại khu vực Tây Nguyên}

\subsection{Thực trạng sản xuất tinh bột sắn tại khu vục Tây Nguyên}

Tây Nguyên bao gồm 5 tỉnh Kon Tum, Gia Lai, Đăk Lăk, Đăk Nông và Lâm Đồng. Tuy vậy, sản lượng sắn tập trung tại 4 tỉnh trừ Lâm Đồng. Sắn được trồng chủ yếu tại Gia lai với 65,8 nghìn tấn năm 2017; chiếm $42,8 \%$ so với tổng diện tích toàn khu vực; tiếp theo là Kon Tum có diện tích 38,6 nghìn ha chiếm $25,1 \%$; tiếp đến là Đăk Lăk có 36,3 nghìn ha, chiếm $23,6 \%$ diện tích toàn vùng; và thấp nhất là Đăk Nông có 13,1 nghìn ha vào năm 2017 [6]. Qua các năm 2015-2017, diện tích trồng sắn có xu hướng giảm bởi sắn có $x u$ hướng thoái hóa, xói mòn đất rất nhanh, do vậy, các địa phương khuyến khích giảm diện tích trồng sắn theo chiều rộng và định hướng phát triển theo chiều sâu như gia tăng năng suất, tập trung vào kỹ thuật canh tác nhằm bảo vệ tài nguyên đất.

Gia Lai có sản lượng lớn nhất trong khu vực, với 1.249,9 nghìn tấn năm 2017 , chiếm $45,3 \%$ toàn khu vực; tiếp đến là Đăk Lăk đạt 703,3 nghìn tấn; chiếm $25,5 \%$; tiếp đến là Kon Tum có 582 nghìn tấn trong năm 2017 và chiếm $21,1 \%$ so với toàn vùng [6]. Như vậy, mặc dù Kon Tum có diện tích khá lớn nhưng sản lượng thấp.

Mặc dù Gia Lai, Đăk Lăk có sản lượng sắn cao
Bảng 3. Diện tích trồng sắn khu vực Tây Nguyên

\begin{tabular}{llll}
\multicolumn{4}{c}{ Đơn vị tính: Nghìn ha } \\
\hline Tỉnh & Năm & Năm & Năm \\
\hline Kon Tum & 2015 & 2016 & 2017 \\
Gia Lai & 63,5 & 39,1 & 38,6 \\
Đắk Lắk & 35,2 & 64,8 & 65,8 \\
Đắk Nông & 18,4 & 15,4 & 36,3 \\
\hline
\end{tabular}

Nguồn: Tổng cuc thống kê, Niêm giám thống kê, năm 2018

nhất tại khu vực nhưng số lượng nhà máy chế biến tinh bột sắn thấp hơn so với Kon Tum. Trong năm 2018, Kon Tum có 8 nhà máy; Gia Lai 6 nhà máy; Đăk Lăk 5 nhà máy và Đăk Nông có 2 nhà máy.

Theo đánh giá của DN hiện sản phẩm tinh bột sắn xuất khẩu của khu vực chủ yếu ở dạng thô, chất lượng kém nên chủ yếu xuất khẩu sang thị trường Trung (dựa vào kết quả phỏng vấn $\mathrm{DN}$ ). Căn cứ dữ liệu các công ty điển hình trên địa bàn, thì tiêu chuẩn chất lượng của các công ty đang thấp hơn tiêu chuẩn do Hiệp hội tinh bột đề xuất.

Dù chất lượng tinh bột sắn tại địa phương không cao nhưng TBS được dùng trong nhiều ngành, mỗi ngành yêu cầu một chỉ tiêu nên mức độ yêu cầu chất lượng tinh bột sắn cũng khác nhau, do vậy doanh nghiệp vẫn có thể tìm thấy thị trường tiêu thụ [7].

Bảng 4. Sản lượng sắn khu vực Tây Nguyên giai đoạn 2015-2017

\begin{tabular}{lccc}
\multicolumn{4}{c}{ Dơn vị tính: Nghìn tấn } \\
\hline Tỉnh & Năm 2015 & Năm 2016 & Năm 2017 \\
\hline Kon Tum & 592,0 & 582,3 & 582,0 \\
Gia Lai & $1.180,9$ & $1.207,1$ & $1.249,9$ \\
Đắk Lắk & 720,7 & 709,4 & 703,3 \\
Đắk Nông & 291,2 & 244,6 & 222,3 \\
\hline
\end{tabular}

Nguồn: Tổng cục thống kê, Niêm giám thống kê năm 2018 
Bảng 5 . Chỉ tiêu chất lượng sản phẩm một số DN trên địa bàn tỉnh Kon Tum

\begin{tabular}{|c|c|c|c|c|c|}
\hline \multirow[t]{2}{*}{ Tiêu chuấn } & \multirow{2}{*}{$\begin{array}{l}\text { Chỉ tiêu chung (ban } \\
\text { hành bởi hiệp hội } \\
\text { sắn Việt Nam) }\end{array}$} & \multicolumn{2}{|c|}{$\begin{array}{l}\text { Công ty TNHH Kon Tum tại Sa } \\
\text { Thầy }\end{array}$} & \multirow{2}{*}{$\begin{array}{l}\text { Chi nhánh nhà } \\
\text { máy TBS } \\
\text { Focosev }\end{array}$} & \multirow[t]{2}{*}{ Công ty Đăk Tô } \\
\hline & & Loại 1 & Loại 2 & & \\
\hline Tinh bột & $>=85 \%$ & $>=85 \%$ & $>=85 \%$ & $>85 \%$ & \\
\hline Độ trắng & $>90 \%$ & $>=90 \%$ & $>=88 \%$ & $>90$ & $91-93 \%$ \\
\hline Tạp chất & & $<=0,05 \%$ & $<=0,15 \%$ & & \\
\hline Xơ & $<=0,2$ & $<=0,05 \%$ & $<=0,1 \%$ & $0,5 \% \max$ & $0,01-0,04$ \\
\hline $\mathrm{SO} 2$ & $<50$ & $<=30$ & $<=30$ & & \\
\hline Độ ẩm & $<=13 \%$ & $<=12 \%$ & $<=12 \%$ & $12,5 \%$ & $10,8-12,3 \%$ \\
\hline Độ dẻo & & $>=650 \mathrm{BU}$ & $>=600 \mathrm{BU}$ & & \\
\hline $\begin{array}{l}\text { Hàm lượng } \\
\text { tro }\end{array}$ & $<=0.2$ & $<=0,1 \%$ & $<=0,25 \%$ & $\operatorname{Max} 0,2 \%$ & \\
\hline Độ PH & $5-7$ & $5,2-6,2$ & $4,5-7$ & $5-7$ & $5,2-6,7$ \\
\hline
\end{tabular}

Nguồn: Tổng hơp dũ liệu của tác giả.

\subsection{Nhận diện các loại lãng phí tại các doanh} nghiệp

\section{a. Lãng phí sản xuất du thùa}

Quy trình sản xuất tinh bột sắn được thực hiện qua các bước: rửa và làm sạch (rửa sơ bộ, tách vỏ và rửa nước); tiếp theo là băm và mài củ. Hai công đoạn này được thực hiện chủ yếu bằng tay. Sau khi băm mài củ sẽ được chuyển qua giai đoạn ly tâm, tách bã, tẩy màu, sau đó qua thu hồi tinh bột, hoàn thiện sấy khô và đóng gói.

Hiện nay việc sản xuất tinh bột sắn không có sự cân bằng trong sản xuất bởi lượng nguyên vật liệu không ổn định, lúc quá nhiều, lúc quá thấp. Điều này khiến lãng phí trong sản xuất rất cao, giá trị trung bình (không có sự cân bằng trong kế hoạch sản xuất) $=3,788$. Tiếp đến là thiết bị hỏng hóc/ không ổn định có giá trị trung bình là 3,476 điểm. Nguyên nhân là do hiện nay các nhà máy đang áp dụng công nghệ từ Trung Quốc chiếm hơn $70 \%$, dẫn đến hiệu quả thu hồi không cao, lượng tiêu hao điện, nước cũng cao hơn so với Sản phẩm chưa đảm bảo chất lượng theo loại 1 khá cao với giá trị trung bình của "sản phẩm có khuyết tật" đạt 3,192 điểm. Kết quả các tiêu chí khác ở mức trên 3 điểm. Điều này cho thấy lãng phí sản xuất dư thừa ở mức khá cao.

\section{b. Lãng phi tồn kho}

Lãng phí tồn kho liên quan đến việc dự trữ nguyên vật liệu, thành phẩm trong quá trình sản xuất. Hiện mỗi nhà máy đều có nhà kho có diện tích từ 1ha đến 3ha nhằm dự trữ thành phẩm trong quá trình sản xuất. Do vậy, chi phí lưu kho khá cao, có 53,6\% lãng phí tại quá trình này. Giá trị trung bình của biến này đạt 3,432 điểm.

Tuy vậy, việc sản xuất tinh bột sắn chỉ tồn kho nhiều ở khâu đầu vào, lượng sắn mua vào và sau sản xuất, trong quá trình sản xuất hầu như việc tồn kho giữa các quá trình thấp, vì khi sắn đưa vào sản xuất thì dây chuyền phải hoạt động liên tục. Do vậy, mặc dù có sự xuất hiện tồn kho giữa các quá trình chiếm $32 \%$; sự tích lũy tồn kho trong hoạt động riêng lẻ chiếm 20,4\% nhưng đây là mức chấp nhận được. Giá trị trung bình của hai biến lần lượt là 2,568 và 2,612 . 


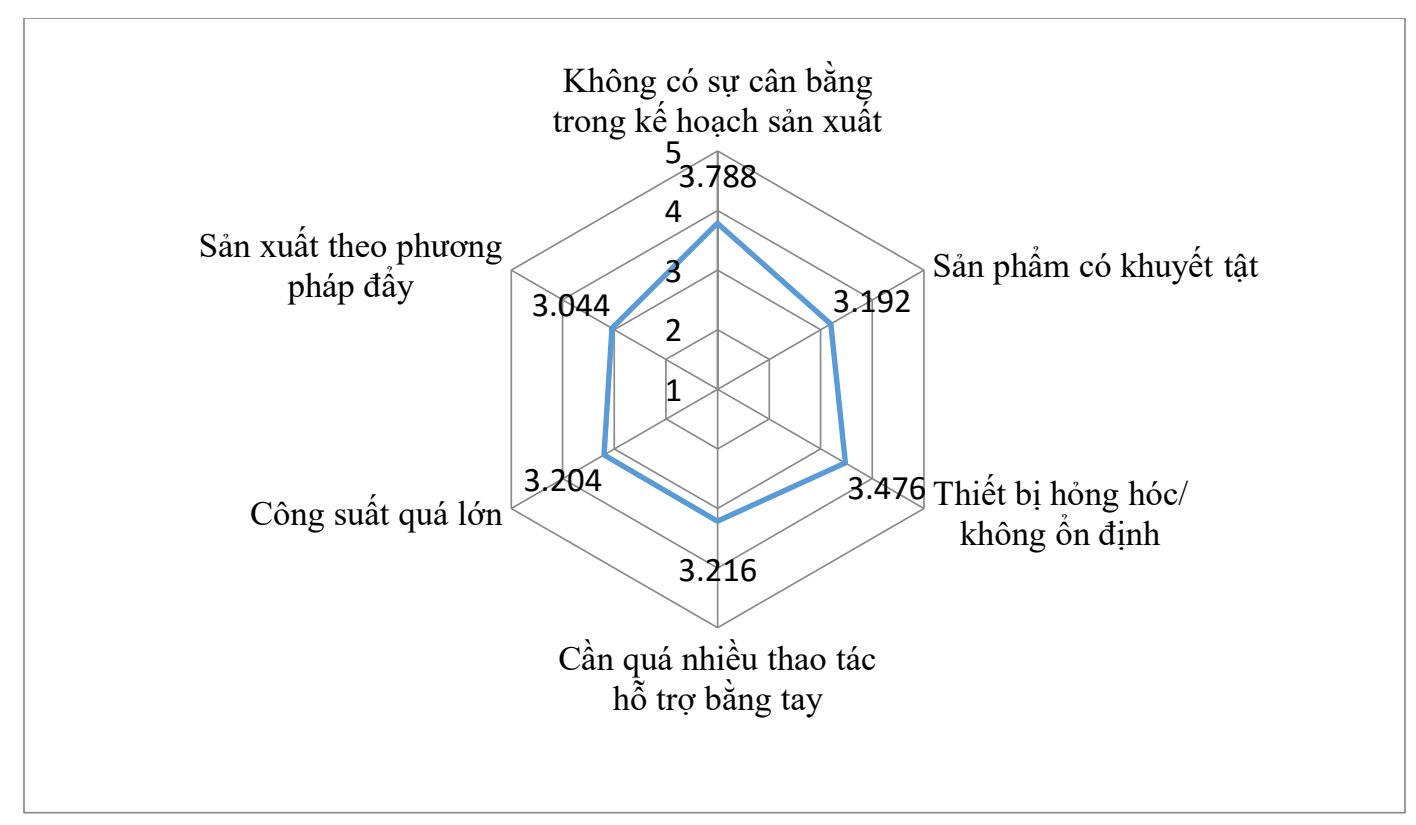

Hình 1. Thống kê về mức độ lãng phí sản xuất dư thừa theo giá trị trung.

Nguồn: Dũ liệu khảo sát của nhóm nghiên cứu năm 2018

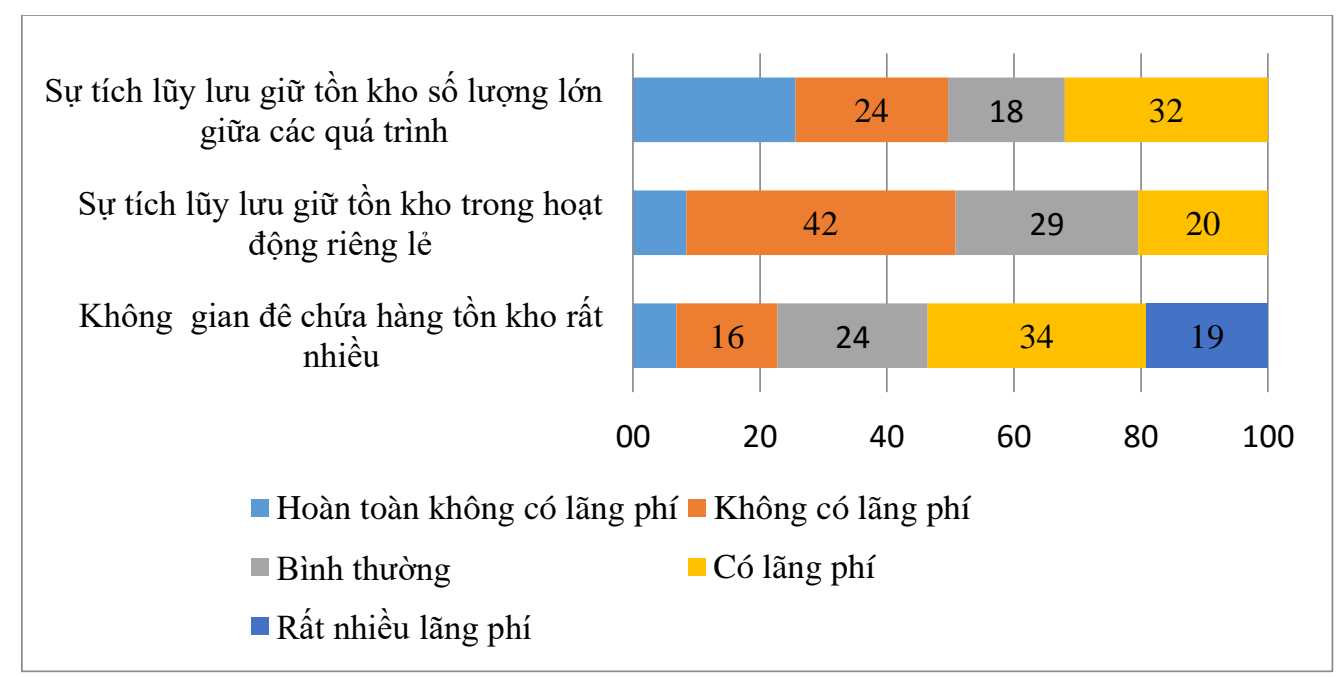

Hình 2. Thống kê mức lãng phí tồn kho.

Nguồn: Dũ liệu khảo sát của nhóm nghiên cứu năm 2018

\section{c. Lãng phí vận chuyển}

Lãng phí vận chuyển đo lường những công việc dư thừa trong quá trình sản xuất. Việc di chuyển bán thành phẩm như bã sắn sau sản xuất, thành phẩm đều phải di chuyển xuống nhà kho khá xa. Điều này khiến cho việc lãng phí tốn khá nhiều chi phí, giá trị trung bình đạt 3,66 điểm, cao nhất trong các loại lãng phí.

Tiếp đến chi phí sắp xếp nguyên vật liệu, thành phẩm, bán thành phẩm qua nhiều khâu trung gian khác nhau... Thông thường chi phí này chiếm khoảng $20 \%$ chi phí bao gồm chi phí trả 
lương cho công nhân bốc xếp, chi phí cho công nhân quản lý kho, chi phí vận hành băng tải bốc dỡ hàng... Giá trị trung bình của chi phí này là
3,388. Do vậy, các nhà quản lý đều đồng ý việc vận chuyển là bắt buộc phải có và phát sinh chi phí là bình thường.

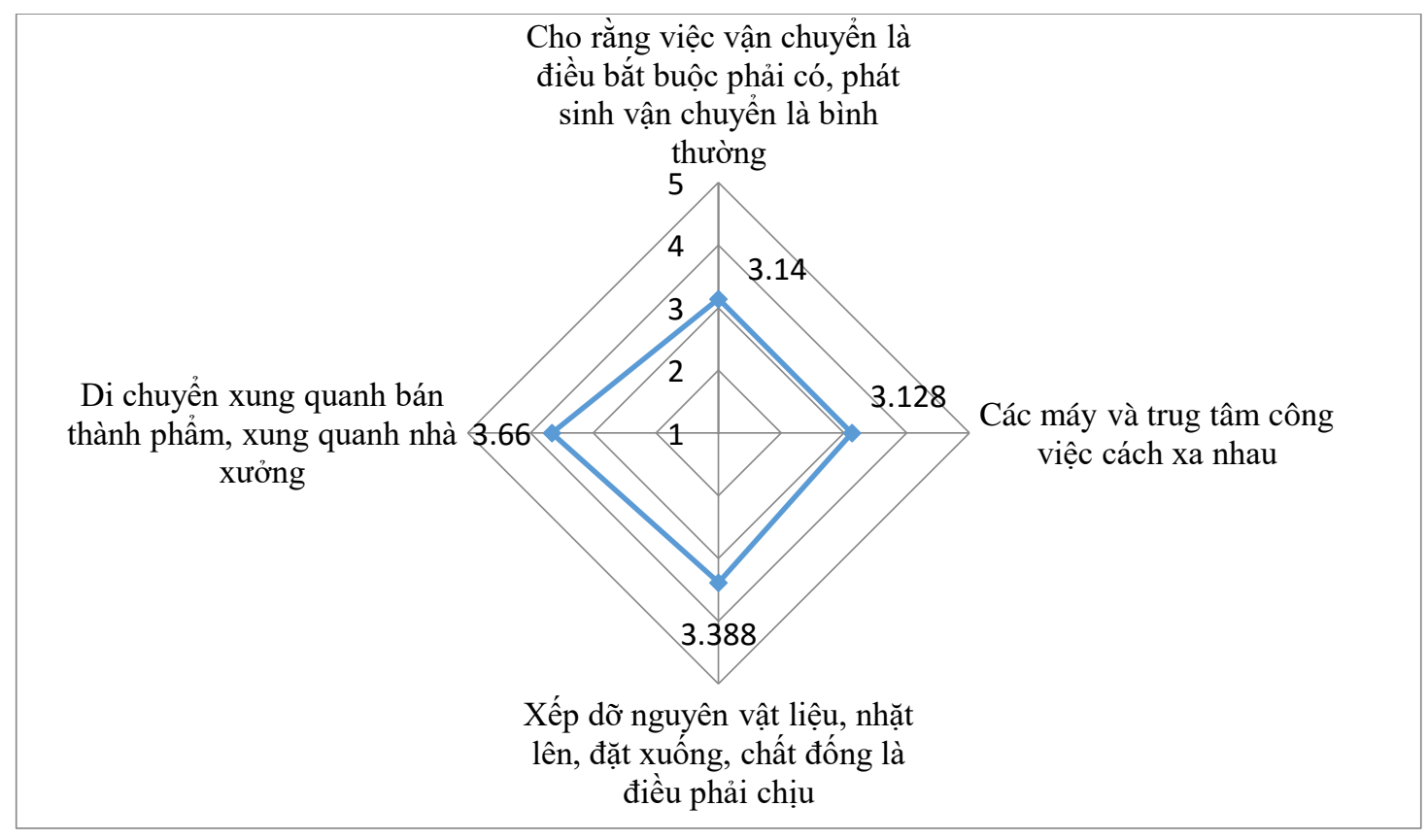

Hình 3. Thống kê mức độ lãng phí của vận chuyển.

Nguồn: Dũ liệu khảo sát của nhóm nghiên cứu năm 2018

\section{d. Lãng phí khuyết tật}

Sai sót khuyết tật bao gồm các sai sót về giấy tờ, thông tin sai lệch sản phẩm, sản xuất sai quy cách, sử dụng quá nhiều nguyên liệu là những loại lãng phí có thể xuất hiện trong quá trình vận hành. Hiện chất lượng sản xuất tinh bột sắn còn khá thấp, cho nên giá bán thấp, khó cạnh tranh với các nước bởi khuyết tật lặp đi lặp lại nhưng không có sự cải tiến đạt 3,52 điểm. Trong quá trình sản xuất, các sai lỗi do con người gây ra có giá trị trung bình là 3,284 ở mức lãng phí khá cao bởi vì công nhân tại các nhà máy chủ yếu là lao động phổ thông, qua đào tạo thấp. Một số công việc trong quá trình sản xuất chưa được kiểm soát tốt và khuyết tật phát sinh khá cao.

Bảng 6. Thống kê mức lãng phí khuyết tật

\begin{tabular}{|c|c|c|c|c|}
\hline Tiêu chí & $\begin{array}{l}\text { Giá trị trung } \\
\text { bình }\end{array}$ & $\begin{array}{l}\text { Độ lệch } \\
\text { chuẩn }\end{array}$ & $\begin{array}{l}\text { Giá trị lớn } \\
\text { nhất }\end{array}$ & $\begin{array}{l}\text { Giá trị nhỏ } \\
\text { nhất }\end{array}$ \\
\hline $\begin{array}{l}\text { Khuyết tật phát sinh trong quá trình } \\
\text { sản xuất }\end{array}$ & 3,077 & 1,105 & 5 & 1 \\
\hline Sai lỗi do con người gây ra & 3,284 & 1,09 & 5 & 1 \\
\hline Khuyết tật do chi tiết hỏng & 2,76 & 1,033 & 5 & 1 \\
\hline $\begin{array}{l}\text { Bỏ sót một số công việc quá trình } \\
\text { trong sản xuất }\end{array}$ & 3,1 & 1,049 & 5 & 1 \\
\hline $\begin{array}{l}\text { Khuyết tật lặp đi lặp lại không được } \\
\text { cải tiến }\end{array}$ & 3,52 & 1,137 & 5 & 1 \\
\hline
\end{tabular}




\section{e. Lãng phí quá trình}

Trong quá trình thực hiện có thể có nhiều thao tác, nguyên công hơn mức cần thiết phải có để tạo ra sản phẩm theo yêu cầu của khách hàng. Do vậy, theo kết quả khảo sát, quá trình sản xuất được kiểm soát khá tốt, mức độ lãng phí ở mức trung bình, cao nhất là quá trình tạo ra sản phẩm có khuyết tật cao đạt 2,740 điểm; có thể bỏ sót một quá trình mà không làm giảm chất lượng đạt 2,724 điểm; cải thiện để ít lãng phí hơn đạt 2,604 điểm. Cụ thể như ở bảng.

Bảng 7. Thống kê mức lãng phí quá trình

\begin{tabular}{lllll}
\hline & $\begin{array}{l}\text { Giá trị } \\
\text { trung bình }\end{array}$ & $\begin{array}{l}\text { Độ lệch } \\
\text { chuấn }\end{array}$ & $\begin{array}{l}\text { Giá trị } \\
\text { lớn nhất }\end{array}$ & $\begin{array}{l}\text { Giá trị } \\
\text { nhỏ nhất }\end{array}$ \\
\hline Quá trình có thể làm ít lãng phí hơn hiện tại & 2,6040 & 1,27345 & 5 & 1 \\
$\begin{array}{l}\text { Có thể bỏ một quá trình nào đó mà không } \\
\text { làm giảm chất lượng sản phẩm }\end{array}$ & 2,7240 & 1,37965 & 5 & 1 \\
Quá trình tạo ra sản phẩm có khuyết tật cao & 2,7400 & 1,42848 & 5 & 1 \\
\hline
\end{tabular}

Nguồn: Dũ liệu khảo sát của nhóm nghiên cứu năm 2018

\section{i. Lãng phí thao tác}

Các lãng phí thao tác bao gồm các chuyển động tay chân hay việc đi lại không cần thiết của công nhân không gắn liền với gia công sản phẩm.

Hiện nay, các thao tác của công nhân hầu như không được chuẩn hóa thành các bước thực hiện công việc, do vậy, việc thiếu chuẩn hóa các bước công việc khiến cho công nhân thực hiện cùng một công việc nhưng kết quả cũng khác nhau. Điều này khiến cho chi phí hoạt động này khá cao với giá trị trung bình đạt 3,54 điểm. Giá trị trung bình của các hoạt động không được chuẩn hóa đạt 3,196 điểm. Hiện tượng đi lại nhiều và hiện tượng quay vòng trong sản xuất có mức lãng phí thấp với giá trị trung bình đạt 2,664 và 2,836 điểm.

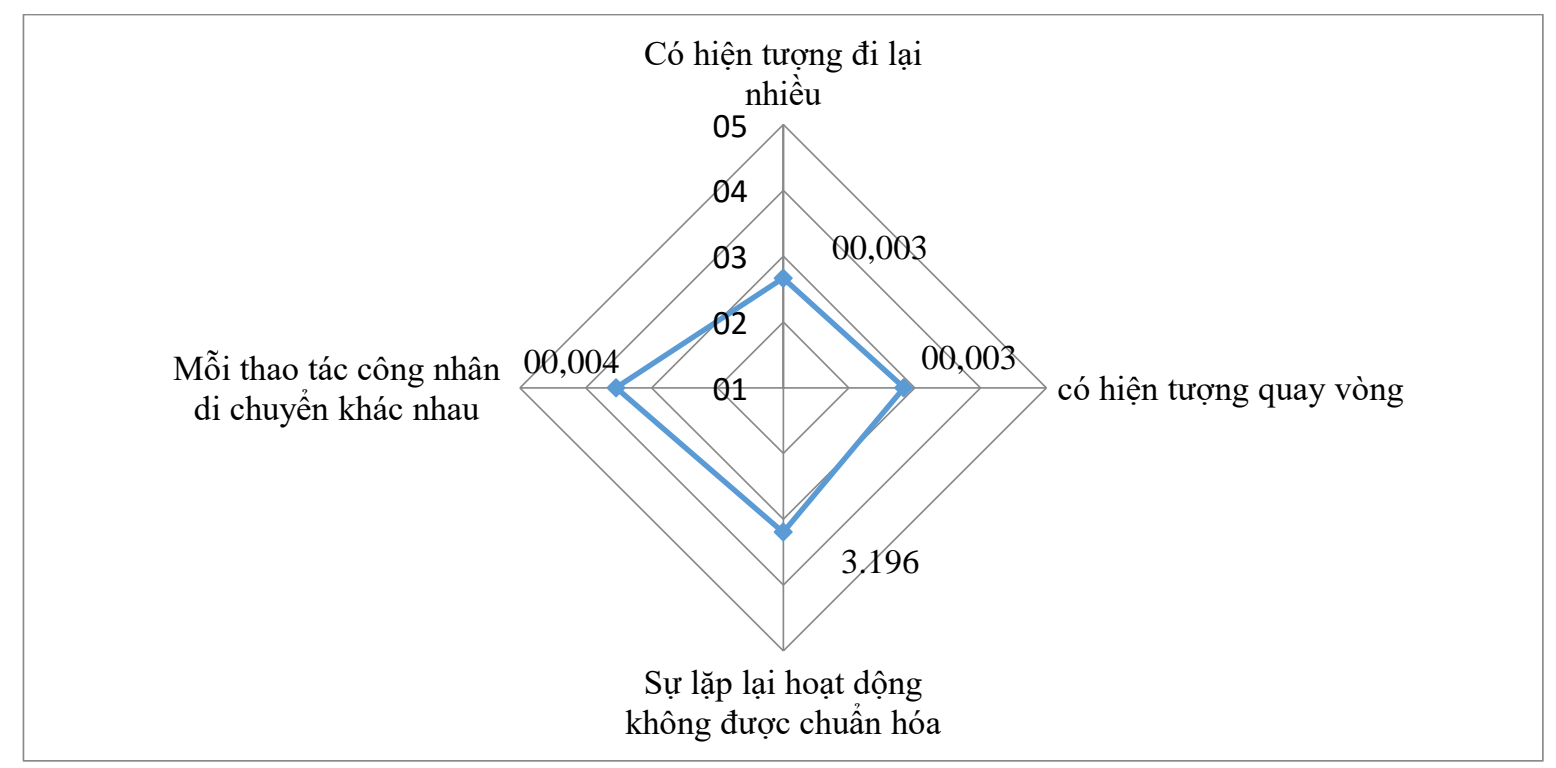

Hình 4. Thống kê mức lãng phí thao tác.

Nguồn: Dũ liệu khảo sát của nhóm nghiên cưu năm 2018. 


\section{f. Lãng phi chờ đợi}

Lãng phí chờ đợi bao gồm thời gian trì hoãn giữa mỗi đợt gia công chế biến sản phẩm, nguyên nhân là do tắc nghẽn hay do dòng sản xuất trong xưởng thiếu hiệu quả. "Việc thiếu vật tư để sản xuất phải chờ" có giá trị trung bình cao đạt 3,5 điểm. Việc thiếu công nhân khiến nhiều người phải chờ có mức lãng phí thấp đạt 1,92 điểm. Đây là yếu tố cần quan tâm của các nhà máy.

Bảng 8 . Thống kê mức lãng phí chờ đợi

\begin{tabular}{lllll}
\hline & $\begin{array}{l}\text { Giá trị } \\
\text { trung bình }\end{array}$ & $\begin{array}{l}\text { Độ lệ̣ch } \\
\text { chuẩn }\end{array}$ & $\begin{array}{c}\text { Giá trị } \\
\text { lớn nhất }\end{array}$ & $\begin{array}{l}\text { Giá trị } \\
\text { nhỏ nhất }\end{array}$ \\
\hline $\begin{array}{l}\text { Thiếu vật tư để sản xuất phải chờ } \\
\begin{array}{l}\text { Thiếu công nhân nên rối rắm trong cân bằng } \\
\text { chuyền nên nhiều người phải chờ }\end{array}\end{array}$ & 3,5 & 1,33 & 5 & 1 \\
\hline
\end{tabular}

Nguồn: Dũ liệu khảo sát của nhóm nghiên cứu năm 2018.

\section{Một số kiến nghị giảm thiểu lãng phí cho các nhà máy sản xuất tinh bột sắn tại Tây Nguyên}

Thứ nhất, nhằm tạo sự cân bằng ổn định trong sản xuất thì việc đảm bảo cung ứng nguyên vật liệu luôn là bài toán chính yếu của các nhà máy chế biến tinh bột sắn. Do vậy, doanh nghiệp có thể ký kết hợp đồng dài hạn với các nông hộ, đảm bảo giá bán, bao đầu ra.... Tại bước này rất cần sự vào cuộc của chính quyền địa phương nhằm đảm bảo mối liên kết này được đảm bảo.

Thứ hai, lãng phí sản xuất do khuyết tật từ sản phẩm, thiết bị hỏng hóc do vậy cần xây dựng các phương án dự phòng cho hoạt động này. Với công nghệ hiện nay mà các doanh nghiệp đang áp dụng rất khó để giảm thiểu chi phí này, cho nên các nhà máy cần từng bước nâng cấp dần công nghệ, chuyển sang sử dụng công nghệ của Thái Lan và của Đức, Châu Âu (những loại công nghệ có khả năng thu hồi sản phẩm cao hơn). Nhà nước có thể hỗ trợ doanh nghiệp trong việc đề xuất các chính sách tín dụng với giá ưu đãi với các ngân hàng. Bên cạnh đó, doanh nghiệp có thể áp dụng thêm các công cụ quản trị tinh gọn như TQM, Kaizen, $5 \mathrm{~S} \ldots$ dể giảm thiểu những lãng phí này.

Thứ ba, lãng phí sản xuất khá cao, do vậy cần xây dựng lại quy trình chuẩn hóa các hoạt động, cụ thể các bước thực hiện nhằm giúp công nhân biết chính xác quá trình làm việc.

Thứ tư, hiện công nhân làm việc tại các nhà máy có trình độ thấp do vậy, muốn nâng cao chất lượng sản phẩm doanh nghiệp cần thực hiện tính toán lợi ích và chi phí trong việc đào tạo, nâng cao nghiệp vụ cho công nhân sản xuất.

Thứ năm, các khuyết tật khi sản xuất lặp đi lặp lại nhiều nhưng không có biện pháp cải tiến. Do vậy, doanh nghiệp cũng cần xây dựng các chính sách khuyến khích người lao dộng đưa ra các sáng kiến nhằm hiệu chỉnh quy trình.

Cuối cùng, các doanh nghiệp nên áp dụng chính sách công nghệ thống nhất xuyên suốt quá trình sản xuất từ khâu thu gom, chế biến, bảo quản. Điều này giúp các doanh nghiệp trong ngành dễ dàng tạo cơ hội thuận tiện cho việc thảo luận, điều chỉnh và phát triển ngành bền vững trong tương lai.

\section{Lời cảm ơn}

Nghiên cứu này được tài trợ bởi Quỹ Phát triển khoa học và Công nghệ Đại học Đà Nẵng trong đề tài có mã số B2017-ĐN08-04.

\section{Tài liệu tham khảo}

[1] Nguyễn Hạnh, 6 tháng đầu năm 2018 xuất khẩu sắn tăng $12,3 \%$ giá trị, https://congthuong.vn/6thang-dau-nam-2018-xuat-khau-san-tang-123-giatri-106170.html, 2018 (Truy cập ngày 10 tháng 11 năm 2018).

[2] D. Lathin, R. Mitchell, Lean manufacturing: techniques, people and culture, Quality Congress Proceedings, Milwaukee. WI., 2001. 
[3] Phan Chí Anh, Quản trị sản xuất tinh gọn một số kinh nghiệm thế giới, Nhà xuất bản Đại học Quốc gia, Hà Nội, 2015.

[4] Jeffrey K. Liker, Phương thức Toyota, Nhà xuất bản tri thức, Hà Nội, 2006.

[5] T. Ohno, Toyota Production System: Beyond Large-scale Production, Productivity Press, Cambridge, MA, 1988.
[6] Tổng cục thống kê, Niêm giám thống kê, Nhà xuất bản Thống kê, Hà Nội, 2018.

[7] Hoàng Thị Kim Anh, Ngô Kế Sương và Nguyễn Xích Liên, Tinh bột sắn và các sản phẩm từ tinh bột sắn, Nhà xuất bản Khoa học Kỹ thuật, Hà Nội, 2006. 